\title{
Comparison of NRZ, RZ-OOK Modulation Formats for FSO Communications under Fog Weather Condition
}

\author{
Mazin Ali A. Ali \\ AL-Mustansiriyah University, College of Science, Physics Department, Iraq-Baghdad
}

\begin{abstract}
In this paper, the performance of an FSO wireless communications system is theoretically analyzed, using NRZ, RZ-OOK modulation formats and a $\mathrm{Si}$ PIN photodiodes receiver over fog weather conditions. Based on different fog models for optical beam propagation horizontally at $850 \mathrm{~nm} 1550 \mathrm{~nm}$ on an FSO, the visibility of weather and power of the transmitter under fog weather are analyzed. The characteristics of bit error rate BER for NRZ and RZ-OOK optical modulation formats are studied under different fog models. Simulation results indicate that the performance of $1550 \mathrm{nmis}$ more suited for an FSO communication system. On the other hand, we discuss the suitability of fog models under these modulation formats.
\end{abstract}

\section{Keywords}

FSO, fog attenuation, visibility, bit error rate BER, NRZOOK, RZ-OOK.

\section{INTRODUCTION}

Free space optics (FSO) is an optical communication technology that uses light propagating in free space to transmit data between two points. This technology is useful where a fiber optic cable is impractical. It is similar to fiber optic communications in that data is transmitted by modulated laser light [1]. Light travels through air faster than glass, so FSO is communication at the speed of light in atmosphere. The stability and quantity of the link is highly dependent on atmospheric factors such as rain, fog, dust and heat. The quality of the transmission is characteristics by the realized bit error rate [2]. Simplest form of FSO links are on-off keying (OOK) modulated links which involve presence and absence of optical pulse for binary ' 1 ' and binary 'o' respectively. Besides ease of modulation and development, following features have made unbeatable option in comparison to conventional RF systems, (i) FSO links use unlicensed IR frequency spectrum (ii) immunity to electromagnetic interference (iii) huge bandwidth and data rates as high as $10 \mathrm{Gbps}$ (iv) FSO links are plug and play devices independent of transmission protocol (v) high end user privacy due to infrared based on line of sight (LOS) [3]. The transmission of modulated light is greatly affected by the atmospheric parameters such as absorption, scattering, and non-selective scattering. Absorption is caused due to gases present in the atmosphere, whereas scattering and nonselective scattering is caused by big sized rain drops. In temperature regions, fog and heavy snow are the primary weather conditions that affect FSO link [4]. The channel characterization in real atmospheric fog is accomplished by using the empirical approach [4-6]. The empirical approach uses the measured visibility and fog attenuation to evaluate the link performance. The visibility is normally measured using a visibility device called the transmissometer. However, it is sometime difficult to accurately measure the visibility and therefore the corresponding fog attenuation because of inhomogeneous for along FSO path. In addition measurement equipment and systems required are complex and very costly [7].

\section{ATTENUATION BY FOG}

For a terrestrial FSO link transmitting optical signal through the atmosphere, the received signal power at a distance, L from the transmitter signal power for FSO is

given by [8, 9] $p_{r}=P_{t} \tau_{t} \tau_{r} \frac{D^{2}}{\theta^{2} \cdot L^{2}} 10^{-\gamma(\lambda) \cdot L / 10}$ (1)

Where $D$ is the receiver diameter, $\theta$ is the full divergence angle; $\gamma$ is the atmospheric attenuation factor $(\mathrm{dB} / \mathrm{km}), \tau_{\mathrm{r}}$ and $\tau_{\mathrm{t}}$ are the receiver and transmitter optical efficiency respectively.

The function of $\gamma(\lambda)$ is the total extinction coefficient per unit length, which represents the attenuation of the transmitted light. It is composed of terms for scattering and absorption, and general it is the sum of the following terms [10] $\gamma(\lambda)=\alpha_{m}(\lambda)+\alpha_{a}(\lambda)+\beta_{m}(\lambda)+\beta_{a}(\lambda)$

The first two terms represent the molecular and aerosol absorption coefficients, respectively while the last two terms are the molecular and aerosol scattering coefficients respectively. The wavelengths used in FSO are basically chosen to coincide with the atmospheric transmission windows $[4,11]$, resulting in the attenuation coefficient being dominated by scattering the attenuation is reduce to:

$$
\gamma_{\text {specific }}(\lambda) \cong \beta_{a}(\lambda)
$$

Attenuation coefficient based on empirical measurement data was calculated by the following empirical model [12]

$$
\beta_{a}(\lambda)=\frac{3.91}{V}\left(\frac{\lambda}{550}\right)^{-\delta}
$$

Where $V$ is the visibility in $(\mathrm{km}), \lambda$ represent the wavelength in $(\mathrm{nm})$. The parameter $\delta$ depends on the visibility distance range, according to Kruse model $\delta$ is given as [13]

$$
\delta=\left\{\begin{array}{l}
1.6, \quad \text { if } V \succ 50 \mathrm{~km} \\
1.3, \quad \text { if } 6 \mathrm{~km} \succ V \succ 50 \mathrm{~km} \\
0.585 . V^{1 / 3}, \text { if } V \prec 6 \mathrm{~km}
\end{array}\right.
$$

While Kim model defines $\delta$ as [4]: 


$$
\delta=\left\{\begin{array}{l}
1.6, \quad \text { if } V \succ 50 \mathrm{~km} \\
1.3, \quad \text { if } 6 \mathrm{~km} \succ V \succ 50 \mathrm{~km} \\
0.16 V+0.34, \quad \text { if } 0.5 \mathrm{~km} \prec V \prec 6 \mathrm{~km} \\
V-0.5, \text { if } 0.5 \mathrm{~km} \prec V \prec 1 \mathrm{~km} \\
0, \text { if } V \prec 0.5 \mathrm{~km}
\end{array}\right.
$$

Al-Naboulsi proposed expressions to predict the wavelength dependent fog attenuation coefficient for the convection and advection fogs for wavelengths from 690 to $1550 \mathrm{~nm}$ [6]. The attenuation coefficient for convection fog is given by:

$$
\gamma_{\lambda}(\mathrm{con})=\frac{0.11478 \lambda+3.8367}{V(\mathrm{~km})}
$$

The attenuation coefficient for advection fog is given by:

$$
\gamma_{\lambda}(a d v)=\frac{0.18126 . \lambda^{2}+0.13709+3.7205}{V(k m)}
$$

The specific attenuation coefficient for both types of fog is

$$
\text { given by } \gamma_{\text {specific }}(\lambda)\left(\frac{d B}{k m}\right)=\frac{10}{\ln (10)} \gamma(\lambda)
$$

\section{SIGNAL TO NOISE RATIO AND BIT ERROR RATE}

The main features of an FSO communication system is the signal to noise ratio SNR. When transmitted optical signals arrive at the receiver, they are converted to electronic signals by photo detectors. There are many types of photo detectors in existence, photodiodes are used almost exclusively in optical communication applications because of their small size, suitable material, high sensitivity, and fast response time [14]. For the PIN photodiode the signal to noise ratio (SNR) is given by [15]:

$$
S N R=\frac{I_{p}^{2}}{2 q B\left(I_{p}+I_{D}\right)+4 K T B F_{n} / R_{L}}
$$

Where $I_{p}$ is the average photocurrent, $q$ is the charge of an electron(C), $B$ represents the bandwidth, $I_{D}$ is the dark current, $T$ is the absolute photodiode temperature $(\mathrm{K}), F_{n}$ is the photodiode figure noise equal to 1 for PIN photodiode, $R_{L}$ is the PIN load resistor. The average photocurrent $I_{p}$ can be expressed as [16]

$$
I_{p}=P_{r} \cdot R
$$

where $\operatorname{Pr}$ is the average optical power received to the photodetector, $R$ is the responsivity of the photodetector.

Another main feature of FSO communication systems is the bit error rate BER [17]. The effect of fog on the Bit Error Rate BER of an FSO link is reported in [18] which correlate the atmospheric transmission with the BER. However, RZ-OOK and NRZ-OOK modulation schemes are widely used in commercial FSO communication systems because of their ease of implementation, bandwidth efficiency and cost effectiveness [19]. The relation BER and SNR for NRZ-OOK modulated signal is as follow [20]:

$$
B E R_{N R Z-O O K}=\frac{1}{2} \operatorname{erfc}\left(\frac{1}{2 \sqrt{2}} \sqrt{S N R}\right)
$$

While BER for RZ-OOK modulated signal is given by [21]:

$$
B E R_{R Z-O O K}=\frac{1}{2} \operatorname{erfc}\left(\frac{1}{2} \sqrt{S N R}\right)
$$

\section{NUMERICAL RESULTS}

In this section, using the above mentioned formulations, the simulation is carried out to study the fog attenuation channel and its effect on FSO optical wireless communication employing RZ-OOK, NRZ-OOK modulation techniques in the transmitter and Si PIN receiver over fog weather condition. The values of the simulation parameters and constants are given in table (1)

\subsection{Attenuation Coefficient for Fog Weather Condition}

In FSO communication system, attenuation is an important indicator. It is meaningful to study achievable distance $\mathrm{L}$ of optical beam under the fog weather. Let us see the effect of the specific attenuation coefficient $\gamma(\lambda)$ on the visibility for optical beam propagation horizontally in FSO. It is shown in Figure $(1,2)$ Specific attenuation coefficient $(\mathrm{dB} / \mathrm{km})$ as a function of visibility $(\mathrm{km})$ for wavelength 850, $1550 \mathrm{~nm}$ under four fog attenuation models (Kim, Kruse, Al-Naboulsi Advection and AlNaboulsi Convection). The simulation shows that we do not find any difference in Specific attenuation coefficient of the different fog model.

Table 1. System parameters used in the simulation [16, 22]

\begin{tabular}{|c|c|}
\hline Parameter & Value \\
\hline Transmission Wavelength $(\lambda)$ & $(850,1550) \mathrm{nm}$ \\
\hline Distance (L) & $1 \mathrm{~km}$ \\
\hline Transmitter power $\left(\mathrm{P}_{\mathrm{T}}\right)$ & $5 \mathrm{mw}$ \\
\hline Optical efficiency of transmitter $\tau_{\mathrm{t}}$ & 0.75 \\
\hline Optical efficiency of receiver $\tau_{\mathrm{r}}$ & 0.75 \\
\hline Laser beam divergence angle $\theta$ & $2 * 10^{-3} \mathrm{rad}$ \\
\hline Receiver diameter & $1 \mathrm{~cm}$ \\
\hline Electron charge (q) & $1.6 \times 10^{-19} \mathrm{C}$ \\
\hline PIN load resistance ( $\left.\mathrm{R}_{\mathrm{L}}\right)$ & $1 \mathrm{k} \Omega$ \\
\hline Boltzmann constant $(\mathrm{k})$ & $1.38 \times 10^{-23} \mathrm{~J} . \mathrm{k}$ \\
\hline Temperature (T) & $298 \mathrm{~K}$ \\
\hline Dark current ( $\left.\mathrm{I}_{\mathrm{D}}\right)$ & $10 \mathrm{nA}$ \\
\hline Responsivity (R) & $0.6 \mathrm{~A} / \mathrm{W}$ \\
\hline Bandwidth (B) & $0.5 \mathrm{GHz}$ \\
\hline
\end{tabular}


It can be observed that the attenuation coefficient does not show wavelengths dependent behavior. In figure. (2) the Specific attenuation coefficient has a minor difference behavior when a visibility less than $1 \mathrm{~km}$, furthermore, Kruse model shows sensitive for long wavelength.

\subsection{BER Characteristics for FSO Communication}

BER plays a crucial role in an optical communication system. We present here simulation results to compare the performance of fog attenuation under different mathematical models. On the other hand, we consider OOK modulation format in the transmitter side because of its simplicity and resilience in the FSO communication system.

\section{2.1 The Impact of the Visibility}

Let us consider the BER performance as a function of the visibility. Figure (3) shows that BER for RZ-OOK modulation format under different fog models when an $850 \mathrm{~nm}$ is used. In this case, we notice that for BER $10^{-10}$, the visibility about $1.7 \mathrm{~km}$ for Kim and Kruse models and its increase for Al-Naboulsi model becomes about 2.15 $\mathrm{km}$. It is noticed in Figure (4) a significant increase in the visibility can be achieved by using a NRZ-OOK modulation format, the maximum data rate is about $2.1 \mathrm{~km}$ for Kim and Kruse model and $2.8 \mathrm{~km}$ for Al-Naboulsi model. Another important simulation was evaluated the performance of the BER for 1550nm under RZ-OOK modulation format. In Figure (5) a significant improvement in the visibility can be achieved by using $1550 \mathrm{~nm}$, for the BER $10^{-10}$, the maximum data transmission is about $1.33 \mathrm{~km}$ for Kim and Kruse model while its about $2.15 \mathrm{~km}$ for Al-Naboulsi model. When we applied NRZ-OOK modulation format, the maximum data transmission is increasing for $1550 \mathrm{~nm}$ compared with $850 \mathrm{~nm}$ for Kim and Kruse Model as shown in figure (6). The maximum data transmission reached to $1.5 \mathrm{~km}$ for Kim and Kruse models, while an approximately occurs in the BER performance for Al-Naboulsi model comparing with figure (4). The maximum data transmission for AlNaboulsi model reached to $2.8 \mathrm{~km}$.

\subsubsection{The Impact of the Transmitter Power}

It has investigated the effect of transmitter power on BER under fog weather condition. We compare the performance of the fog models when an RZ-OOK and NRZ-OOK used as a modulation formats under a PIN photodiode. Figure (7) shows BER versus transmitter power when a distance $1 \mathrm{~km}$ and visibility $1 \mathrm{~km}$. If we consider required $10^{-10}$, when used a RZ-OOK modulation format and $850 \mathrm{~nm}$ as a carrier signal the transmitter power about $-40 \mathrm{dBm}$ for Kim and Kruse models while the increase for Al-Naboulsi model reached to $-32 \mathrm{dBm}$. When a NRZ-OOK applied as is evident in Figure (8). An increase occurs in the BER leads to increase in the transmitter power reached to $-35 \mathrm{dBm}$ for Kim and Kruse models while -28 for Al-Naboulsi model.

We performed the same calculations also for $1550 \mathrm{~nm}$ under the same conditions. Figure (9) shows the BER for RZ-OOK modulation format, where an improvement occurs when applied $1550 \mathrm{~nm}$ as a carrier signal. In this case, notice that for BER $10^{-10}$, a decreasing occur in the transmitter power reached to $-48 \mathrm{dBm}$ and $-46 \mathrm{dBm}$ for Kruse and Kim models respectively, and $-33 \mathrm{dBm}$ for Al-
Naboulsi model. In figure (10) assume that an FSO communication system operating under NRZ-OOK modulation format, it is clear that the BER required an increasing for the transmitter power. In this case, the data of the transmission about $-45 \mathrm{dBm}$ for Kruse model and $44 \mathrm{dBm}$ for Kim model while reached to $-30 \mathrm{dBm}$ for $\mathrm{Al}$ Naboulsi model.

\section{CONCLUSION}

This paper provides a theoretical performance analysis of an FSO wireless communication link using NRZ-OOK and RZ-OOK modulation formats in the transmitter and $\mathrm{Si}$ PIN as a receiver with four mathematical models for fog attenuation. The specific attenuation coefficient of the laser beam through fog weather has a significant effect on the performance of FSO communication systems. The effect of fog attenuation, visibility, and transmitter power are investigated. The suitable choice of wavelength has a strong influence on the attenuation coefficient, which leads to long transmission in free space. When weather has increased visibility, this causes a decrease in attenuation coefficient. The BER characteristics of the NRZ and RZOOK modulation formats under different fog models are studied. The results show that the wavelength $1550 \mathrm{~nm}$ has a greater advantages than the other wavelength, therefore, a $1550 \mathrm{~nm}$ is a more suitable wavelength compared with $850 \mathrm{~nm}$ for FSO under fog effect. Furthermore, the performance of RZ-OOK is better than the NRZ-OOK, the Kruse model is more sensitive for fog attenuation compared with the other models.

\section{REFERENCE}

[1] Willebrand. H, Ghuman, B. S., .Free-Space Optics: Enabling Optical connectivity in today's networks, SAMS Publishing, Indianapolis, 2002.

[2] Andrews, L. C., .Fuild Guide to atmospheric optics, SPIE press, USA, 2004.

[3] Miglant, R., Singh, M. L., performance evaluation of free space optical link using mid and far infrared wavelengths in turbulent atmospheric conditions, $4^{\text {th }}$ international workshop on fiber optics in access network(FOAN), 2001.

[4] Kim, I. I., McArthur, B., Korevaar E., comparison of laser beam propagation at $785 \mathrm{~nm}$ and $1550 \mathrm{~nm}$ in fog and haze for optical wireless communications, Proc. SPIE, vol.214, no. 2, 2001.

[5] Nadeem, F., Javornik T., Leitgeb, E., Kvicera, V., and Kandus, G., continental fog attenuation empirical relationship from measured visibility data, journal of radioEngineering vol. 19, no. 4, 2010.

[6] Naboulsi, M. A., Forne, F. D., Sizun, H., Gebhart, M., Leitgeb, E., Muhammed, S. S., Flecker, B. and Chlestil, C., measured and predicted light attenuation in dense coastal upslope fog at 650,850 , and $950 \mathrm{~nm}$ for free-space optics applications, journal of optical engineering, vol. 47, no. 3, 2008.

[7] Pesek, J., Ijaz, M. , Ghassemlooy, Z., Fiser, O., Rajbhandsri, S., measuring the fog attenuation in an indoor free space optical laboratory chamber, international conference on applied electronics, Czech republic, September, 2012. 
[8] Majumdar, A., Free-Space Laser Communications: Principles and Advanced, springer science+business media, LLC, 2008.

[9] Shaik, K.S., Atmospheric propagation effects relevant to optical communication. TDA progress report, 1988.

[10] Hemati, H., Deep space optical communications, in deep space communications and navigation series California, 2005

[11] Bloom, S., Korevaar, E., Shuster, J., and Willebrand, H., understanding the performance of free-space optics, journal of networking, vol. 2, pp. 178-200, 2003.

[12] Fadhil, H. A., Amphawan, A.H., Shamsuddin, A. B., Thanaa Hussein Abd, Hamza Al-Khafaji, M. R., Aljunid, S. A., and Nasim Ahmed, optimization of free space optics parameters: An optimum solution for bad weather conditions, Elsevier, Optik, vol.124, 3969-3973, 2013.

[13] Kruse, P. W. , McGlauchlin, L. D. , and McQuistan, R. B., Elements of infrared technology generation, transmission, and detection, Newyork: J. Wiley and Sons, 1962.

[14] Keiser, G., optical fiber communications, McGrawHill Company, 2000.

[15] Kharraz, O., Forsyth, D., PIN and APD photodetector efficiencies in the longer wavelength range 13001500nm, Elsevier, Optik, vol. 124, pp. 2574-2576, 2013.
[16] Keiser, G., optical essential communications, McGraw-Hill Company, 2004

[17] Tyson, R. K., Bit-Error Rate for free - space adaptive optics laser communications, Journal of Optical Society of America A, vol.19, no. 4, pp. 753758, 2002.

[18] Strickland, B. R., Lavan, M. J., Woodbridge, E., and Chan, V., Effects of fog on the bit -error rate of a free space laser communication system, journal of applied optics, vol.38, pp. 424-431, 1999.

[19] Liu, N., Zhong, W. D., He, Y., Heng, H., and Cheng, T. H., Comparison of NRZ and RZ modulations in laser intersatellite communication systems, proceedings of the 2008 international conference on advanced infocomm technology, Shezhen China, pp. 677,2008 .

[20] Andrews, L. C., Philips, R. L., Laser beam propagation through random media, $2^{\text {nd }}$ edition, SPIE Optical Engineering Press, Bellingham, WA, 2005.

[21] Trisno, S., design and analysis of advanced free space optical communication systems, Ph. D thesis, University of Maryland, 2006.

[22] Agrawal, G. P., Fiber-Optic communication system, John Wiley and Sons, $4^{\text {th }}$ edition, 2010.

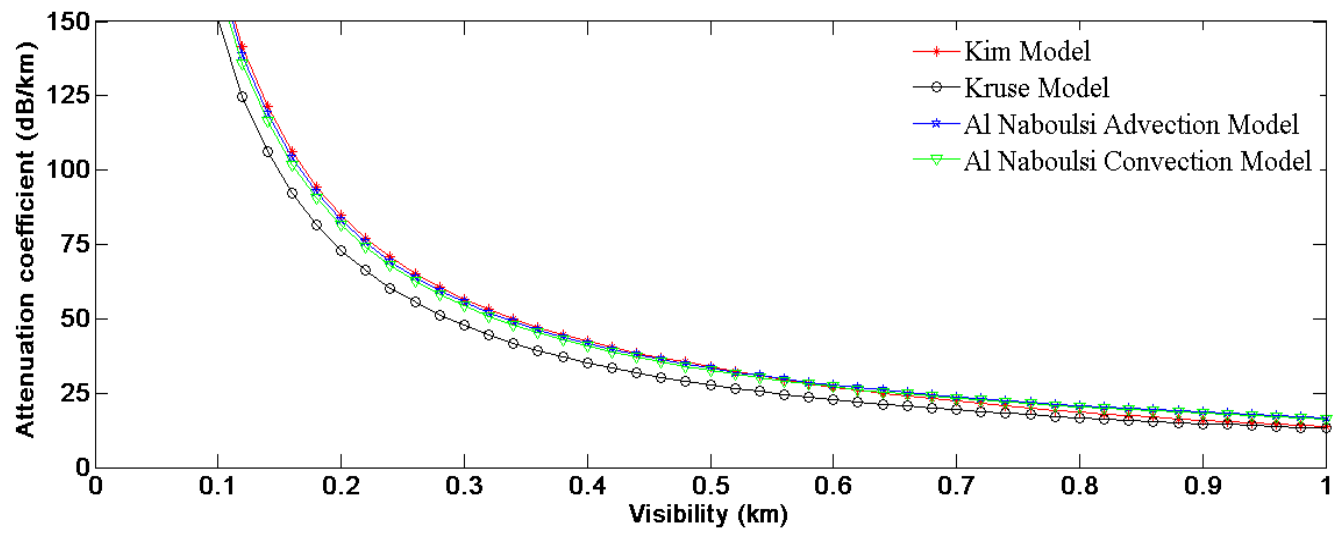

Fig (1) Specific attenuation coefficient for different models for $850 \mathrm{~nm}$

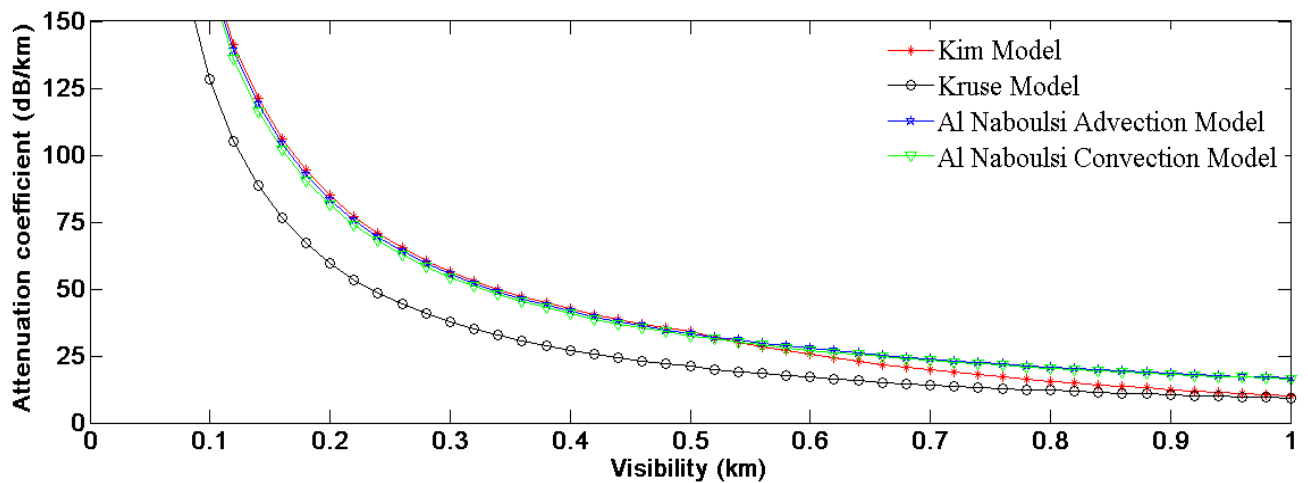

Fig (2) Specific attenuation coefficient for different models for $1550 \mathrm{~nm}$ 


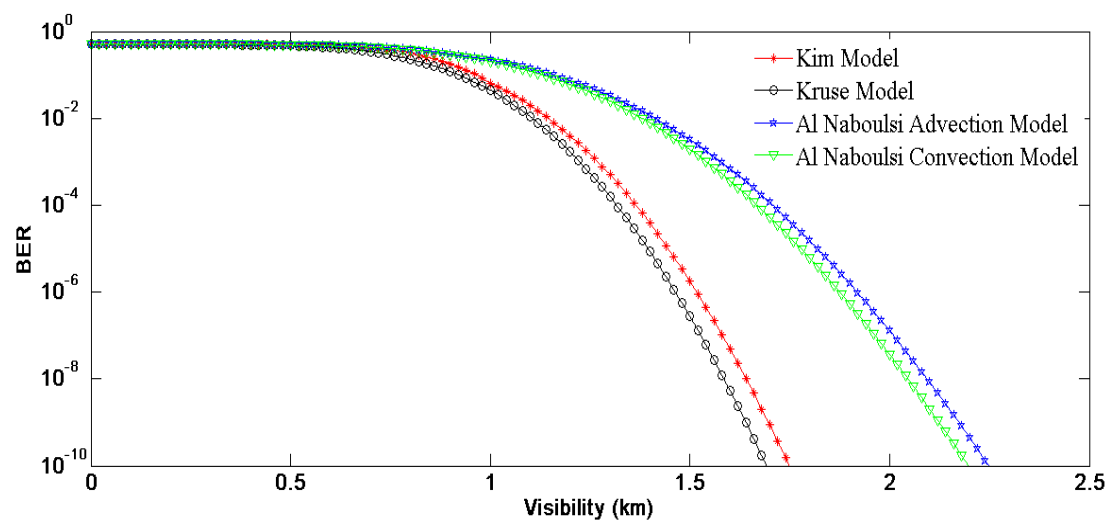

Fig. (3) BER as a function of visibility for RZ-OOK, $850 \mathrm{~nm}$.

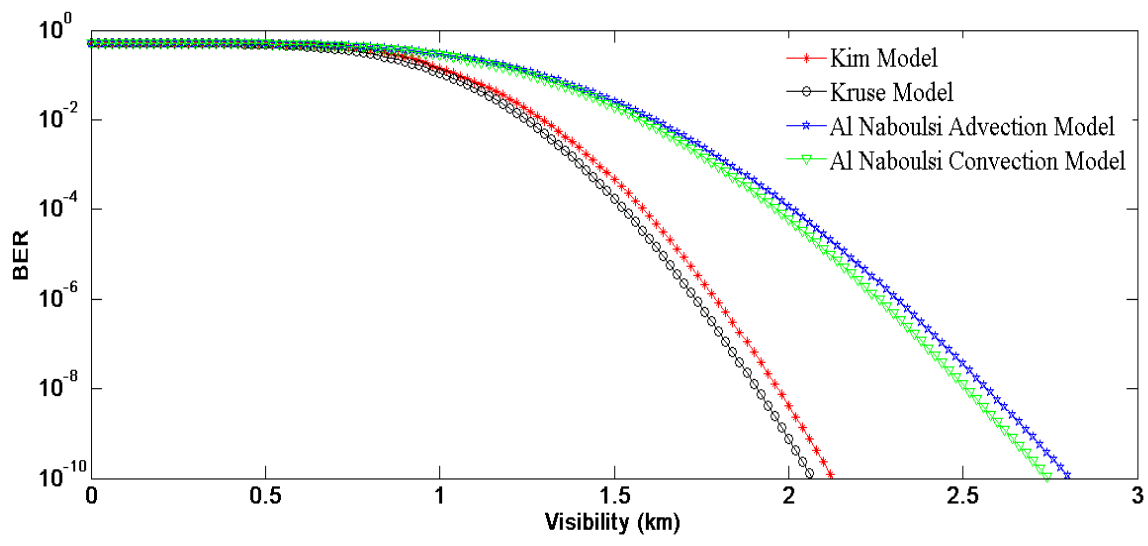

Fig. (4) BER as a function of visibility for NRZ-OOK, $850 \mathrm{~nm}$.

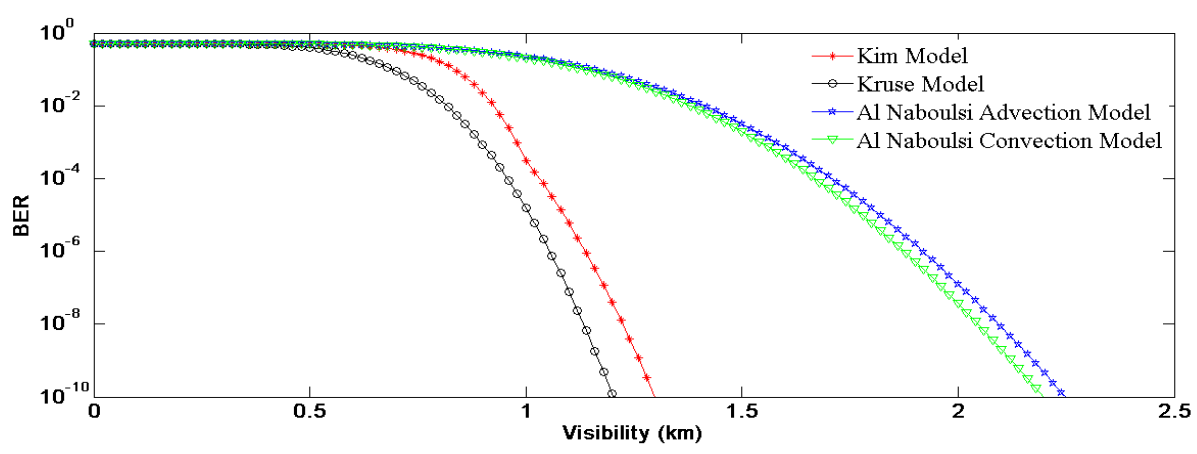

Fig. (5) BER as a function of visibility for RZ-OOK, $1550 \mathrm{~nm}$.

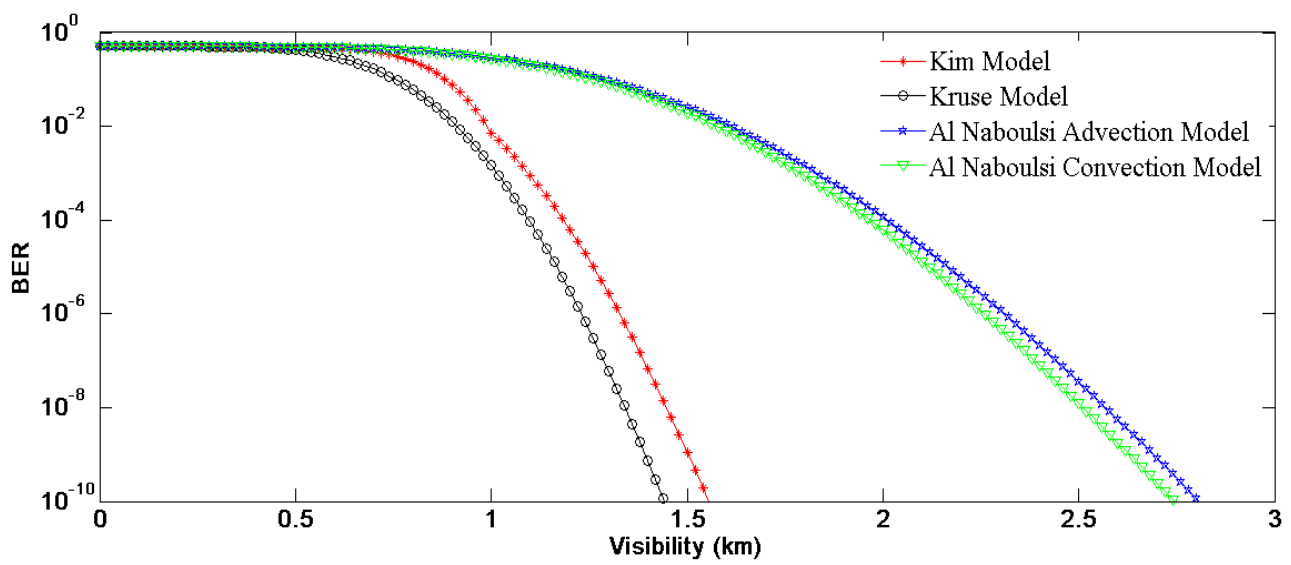

Fig. (6) BER as a function of visibility for NRZ-OOK, $1550 \mathrm{~nm}$. 


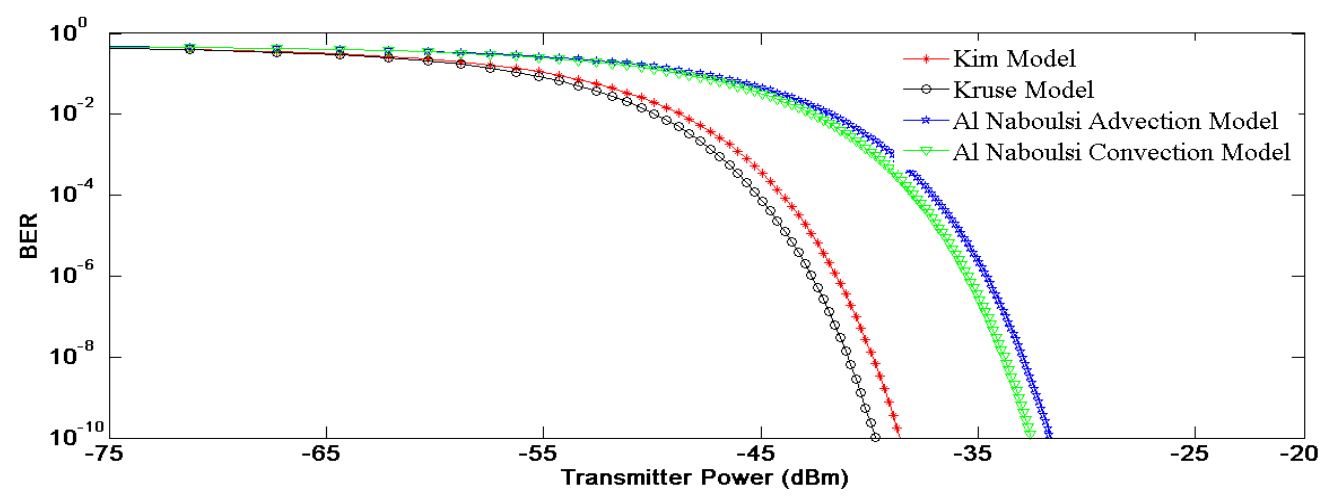

Fig. (7) BER versus Transmitter Power for RZ-OOK 850 nm, V=1 km.

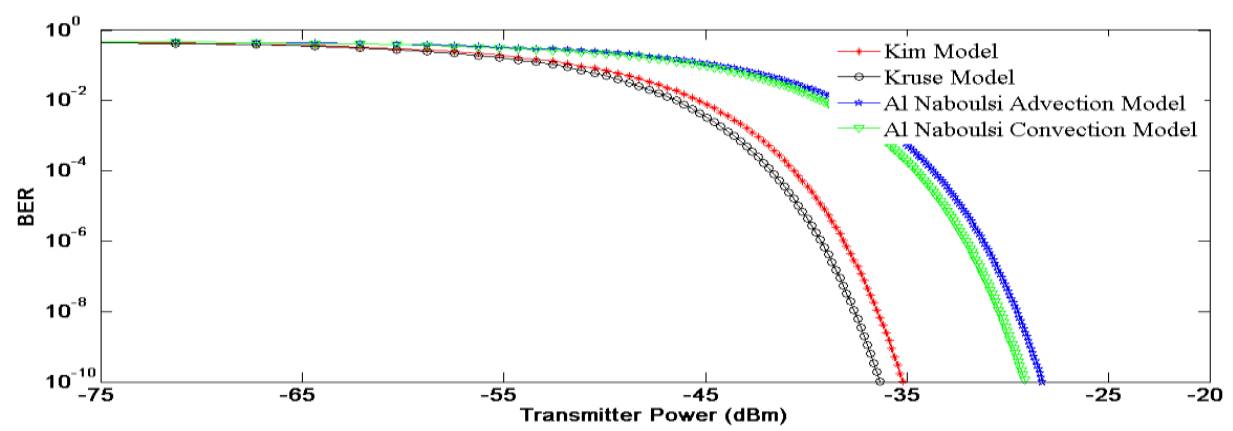

Fig. (8) BER versus Transmitter Power for NRZ-OOK 850 nm, V=1 km.

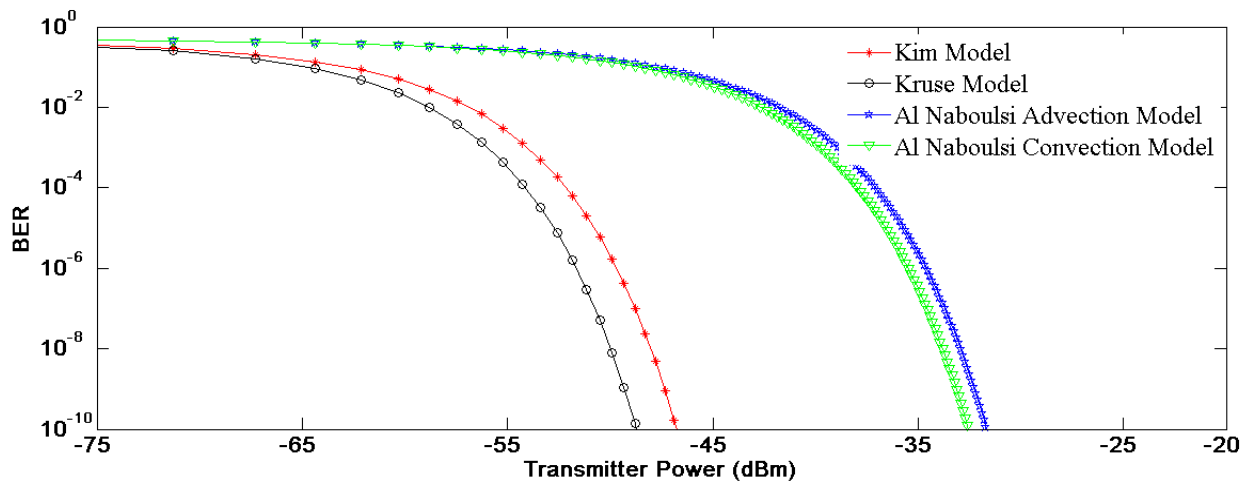

Fig. (9) BER versus Transmitter Power for RZ-OOK, 1550 nm, V=1km

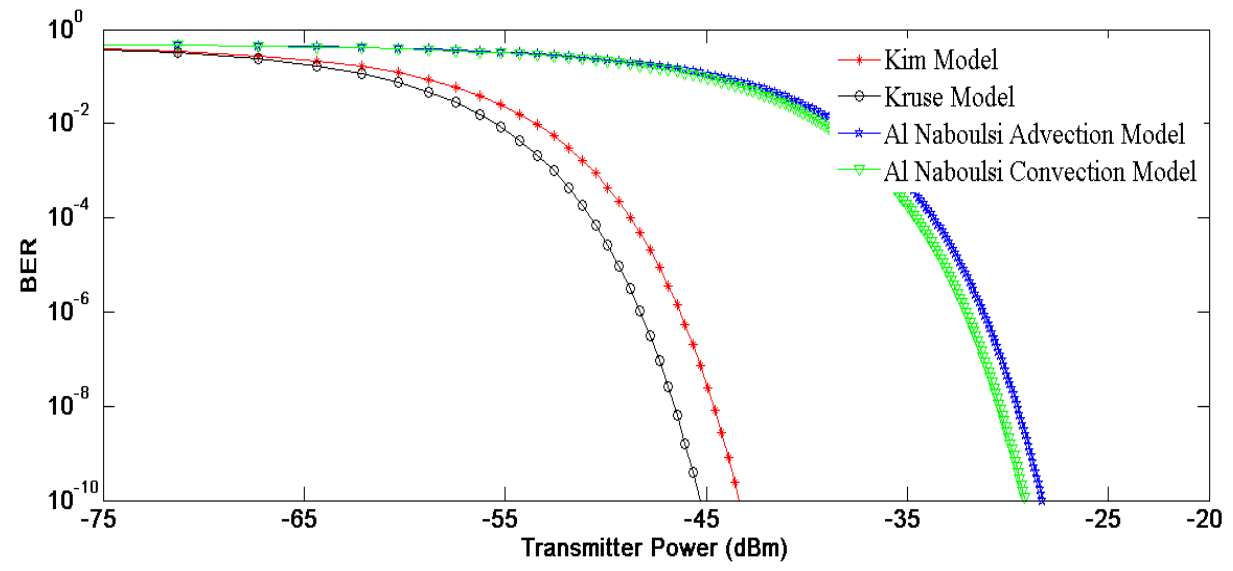

Fig. (10) BER versus Transmitter Power for NRZ-OOK, 1550 nm, V=1 km 